\title{
Modelling and Stability Analysis of Brushless Doubly Fed Generators
}

\author{
Abderahmane Ganouche ${ }^{\star 1}$, Hacene Bouzekri ${ }^{2}$, Antar Beddar ${ }^{3}$ \\ ${ }^{1,2,3}$ Department of Electrical Engineering, University 20 August 1955 Skikda, Algeria \\ P.B. 26 El-Hadaiek Road, Skikda, 21000, Algeria \\ *Corresponding author, e-mail: ganouche.a@gmail.com ${ }^{1}$, habouzekri@gmail.com², antar_tech@hotmail.fr ${ }^{3}$
}

\begin{abstract}
The brushless doubly-fed machine (BDFM) continues to attract increasing interest for applications in wind generation where, robustness and low servicing costs are its principles advantages. The construction aspect of the BDFM has been widely studied and currently this machine can be build with good performances. However, the control aspect remains difficult to achieve and some studies show that the BDFM is less stable than the doubly-fed induction machine. To explore the BDFM stability in all operating mode, this paper proposes a stability analysis of a grid-connected variable speed wind turbinebased BDFM. For this purpose, a linearized small signals mathematical model is proposed which takes into account both grid and control disturbances. Then, the effect of electrical parameters variation and operating speed change on the stability of the BDFM has been studied. The stability has been investigated through simulation implementation. The obtained results demonstrate the validity and the superiority of the proposed model.
\end{abstract}

Keywords: Brushless Doubly-Fed Machine, stability analysis, mathematical model, operating point, small signal

Copyright $@ 2017$ Universitas Ahmad Dahlan. All rights reserved.

\section{Introduction}

In recent years, the wind power generation has been greatly commercialized because of the low air pollution and the high fuel efficiency [1-2]. The most used generator in wind power generation is the Doubly Fed Induction Machine (DFIM) because of its small volume and low power converter [3-5]. However, the DFIM is a wound rotor induction machine and has brushes and slip rings, so it requires periodic services, thus induces extra maintenance costs [6]. To overcome the drawbacks of the DFIM, a good alternative has been proposed, the Brushless Doubly Fed Machine (BDFM) [6-7].

The first literature reports on the BDFM structure can be traced back to the early years of the twentieth century when [8] proposed a topology based on two DFIMs rotating on the same shaft with their rotor windings connected to form what was known as the "cascaded DFIMs'. This structure was further improved by allowing a special single rotor to couple two independent three-phase windings known as power winding and control winding located on the stator. The stator windings are designed with different pole pair numbers to eliminate direct magnetic coupling [9]. In generation mode, the power winding is connected directly to the grid and the control winding is fed by a back-to-back converter [10].

To obtain synchronous operation of the BDFM, an electromagnetic cross-coupling effect between the power winding and the control winding must be achieved such that the induced rotor currents evolve with equal frequencies.

Recently, many mathematical models have been proposed to describe the steady-state and the dynamic behaviour of the BDFM for exploitation in implementing control strategies and studying its stability $[11-12,7]$.

In the reported literature, the stability of the BDFM has been studied by a lot of authors. [13] studied the stability of a cascaded DFIMs mounted in a single frame by using small signal analysis; they concluded that the cascaded DFIM has some areas of instability in open loop operation. More recently, the same authors investigated the impact of parameters change on the stability of the cascaded DFIM and demonstrate that the real part of the dominant poles of the cascaded DFIM is dependent on the speed and load [14]. Later on, [15] analyzed the open- 
loop stability characteristics of the BDFM in equilibrium points based on the generalized theory of Floquet; they showed by simulation results a possible instability when the frequency of the control winding is high, but their experimental results disagree with those obtained by computer simulation. A decade later, [16] studied the open-loop stability of a small signal $d-q$ unified reference frame model of the BDFM, and showed that stability area is dependent on machine parameters. One year later, [17] studied the stability of the BDFM under closed loop scalar current control, and showed by experimental BDFM set-up a stable behaviour along all the operation range.

It should be recognised that a contradiction arises between the arguments that the BDFM could attain a wide range open-loop stable operation $[15,17]$ and those that the BDFM is open-loop conditionally stable $[13,16]$. From a control point of view, although of the discrepancy, nonetheless, closed-loop control is perpetually required to increase the stability margin and enhance dynamic performance. Consequently, more researchers became concentrated on closed-loop control schemes [18-20]. In previous works, the absence of a clear mathematical model leads to a weak stability analysis of the BDFM in generation mode, where their eigenvalues analysis cannot be performed directly.

To find analytical justifications for this problem, this paper proposes a new mathematical model of the grid connected BDFM taking into account both control and grid disturbances. With the proposed mathematical model of the BDFM, a stability study is carried out. The proposed BDFM mathematical model is a transfer matrix $2 \times 4$ between the stators voltages and the produced currents. The denominator of the transfer matrix is used to extract the eigenvalues and analyse the stability characteristics of the BDFM. Moreover, the effects of electrical parameters variation on the BDFM-stability is presented and widely investigated.

This paper is organized as follows. In Section 2 the small signal unified reference frame model of the BDFM in a wind energy system is derived. Section 3 presents a BDFM-stability study based on the proposed model and applied to a selected benchmark machine. Finally, the conclusion is drawn in section 4 .

\section{Mathematical Model of the BDFM}

The principle of using a grid-connected BDFM in generation mode in a wind turbine is illustrated in Figure 1. In this variable speed structure, the control winding is connected to the grid through a partially rated power electronic converter.

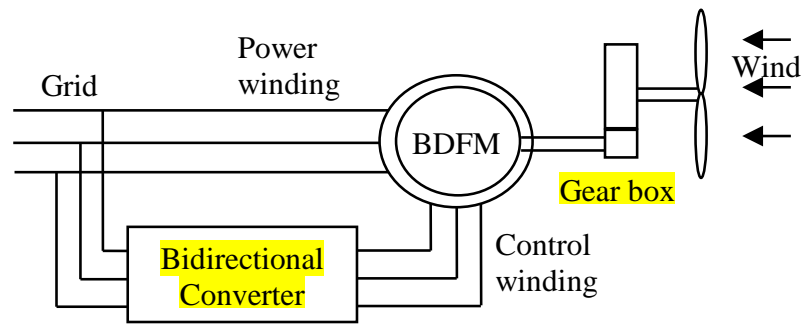

Figure 1. The BDFM in wind energy conversion system

Based on the set of electromagnetic equations of the BDFM expressed in the $a-b-c$ coordinate system, the machine model aligned with the power winding flux and expressed in the $d-q$ unified reference frame is given by the following expressions [12]

The voltage equations are:

$$
\begin{aligned}
& v_{p}^{d q}=R_{s p} i_{p}^{d q}+\frac{d}{d t} \varphi_{p}^{d q}+j \omega_{p} \varphi_{p}^{d q} \\
& v_{c}^{d q}=R_{s c} i_{c}^{d q}+\frac{d}{d t} \varphi_{c}^{d q}+j \alpha \varphi_{c}^{d q}
\end{aligned}
$$




$$
v_{r}^{d q}=R_{r} r_{r}^{d q}+\frac{d}{d t} \varphi_{r}^{d q}+j \beta \varphi_{r}^{d q}
$$

The magnetic flux equations are:

$$
\begin{aligned}
& \varphi_{p}^{d q}=L_{s p} i_{p}^{d q}+L_{h p} i_{r}^{d q} \\
& \varphi_{c}^{d q}=L_{s c} i_{c}^{d q}+L_{h} i_{r}^{d q} \\
& \varphi_{r}^{d q}=L_{r} i_{r}^{d q}+L_{h p} i_{p}^{d q}+L_{h c} i_{c}^{d q}
\end{aligned}
$$

With:

$$
\begin{aligned}
& \alpha=\omega_{p}-\left(P_{p}+P_{c}\right) \omega_{r} \\
& \beta=\omega_{p}-P_{p} \omega_{r}
\end{aligned}
$$

Where $\alpha(\beta)$ represents the relative angular velocity between the reference frame $d$ - $q$ and the control winding (rotor) reference related to a $p_{c}\left(p_{p}\right)$ pole-pair-type distribution [12]. Substitution of the flux Eqns. (4)-(6) into the Voltage Eqns. (1)-(3) yields:

$$
\begin{aligned}
& {\left[\begin{array}{c}
v_{p}^{d} \\
v_{p}^{q}
\end{array}\right]=\left[\begin{array}{cc}
R_{s p}+q L_{s p} & -\omega_{p} L_{s p} \\
\omega_{p} L_{s p} & R_{s p}+q L_{s p}
\end{array}\right]\left[\begin{array}{c}
i_{p}^{d} \\
i_{p}^{q}
\end{array}\right]+\left[\begin{array}{cc}
q L_{h p} & -\omega_{p} L_{h p} \\
\omega_{p} L_{h p} & q L_{h p}
\end{array}\right]\left[\begin{array}{c}
i_{r}^{d} \\
i_{r}^{q}
\end{array}\right]} \\
& {\left[\begin{array}{c}
v_{c}^{d} \\
v_{c}^{q}
\end{array}\right]=\left[\begin{array}{cc}
R_{s c}+q L_{s c} & -\alpha L_{s c} \\
\alpha L_{s c} & R_{s c}+q L_{s c}
\end{array}\right]\left[\begin{array}{c}
i_{c}^{d} \\
i_{c}^{q}
\end{array}\right]+\left[\begin{array}{cc}
q L_{h c} & -\alpha L_{h c} \\
\alpha L_{h c} & q L_{h c}
\end{array}\right]\left[\begin{array}{c}
i_{r}^{d} \\
i_{r}^{q}
\end{array}\right]} \\
& {\left[\begin{array}{c}
v_{r}^{d} \\
v_{r}^{q}
\end{array}\right]=\left[\begin{array}{cc}
R_{r}+q L_{r} & -\beta L_{r} \\
\beta L_{r} & R_{r}+q L_{r}
\end{array}\right]\left[\begin{array}{c}
i_{r}^{d} \\
i_{r}^{q}
\end{array}\right]+\left[\begin{array}{cc}
q L_{h p} & -\beta L_{h p} \\
\beta L_{h p} & q L_{h p}
\end{array}\right]\left[\begin{array}{c}
i_{p}^{d} \\
i_{p}^{q}
\end{array}\right]+\left[\begin{array}{cc}
q L_{h c} & -\beta L_{h c} \\
\beta L_{h c} & q L_{h c}
\end{array}\right]\left[\begin{array}{c}
i_{c}^{d} \\
i_{c}^{q}
\end{array}\right]}
\end{aligned}
$$

Where $q=\frac{d()}{d t}$.

Given the nonlinearities inherent to the previous model represented by Eqns. (9)-(11), a simplification can be justified under the assumption of small variations in the rotor's mechanical angular speed. Thus, for the case of a wind energy conversion system operating around an angular speed value $\omega_{r o}$ which depends on the wind nominal speed $\left(\omega_{r}=\omega_{r o}+\Delta \omega_{r}, \Delta \omega_{r} \approx 0\right)$, Equation (7) and (8) become:

$$
\begin{aligned}
& \alpha=\omega_{p}-\left(P_{p}+P_{c}\right) \omega_{r o} \\
& \beta=\omega_{p}-P_{p} \omega_{r o}
\end{aligned}
$$

Where the new subscript $o$ denotes the steady state quantities. Now, combining Eqns. (9), (10) and (11) allows expression of the power winding current vector as a linear function of control winding and power winding voltage vector as follows: 


$$
\left[\begin{array}{c}
\Delta I_{p}^{d} \\
\Delta I_{p}^{q}
\end{array}\right]=\left[\begin{array}{cccc}
G_{c 11}(s) & G_{c 12}(s) & G_{p 11}(s) & G_{p 12}(s) \\
-G_{c 12}(s) & G_{c 11}(s) & -G_{p 12}(s) & G_{p 11}(s)
\end{array}\right] \cdot\left[\begin{array}{c}
\Delta V_{c}^{d} \\
\Delta V_{c}^{q} \\
\Delta V_{p}^{d} \\
\Delta V_{p}^{q}
\end{array}\right]
$$

The transfer function matrix in Eqn. (14), defines the BDFM as a four-input two-output linear system. Entries $G_{c 11}(s), G_{c 12}(s), G_{p 11}(s)$ and $G_{p 12}(s)$ are functions of both the rotor's nominal operating mechanical angular speed $\omega_{r o}$ and the electrical parameters of the machine. These entries are given by:

$$
\begin{aligned}
& G_{c 11}(s)=\frac{b_{c 1}(s)}{a(s)}, G_{c 12}(s)=\frac{b_{c 2}(s)}{a(s)} \\
& G_{p 11}(s)=\frac{b_{p 1}(s)}{a(s)}, G_{c 12}(s)=\frac{b_{p 2}(s)}{a(s)}
\end{aligned}
$$

Where $a(s), b_{c 1}(s), b_{c 2}(s), b_{p 1}(s)$ and $b_{p 2}(s)$ are polynomials in the Laplace variable 's':

$$
\begin{aligned}
& b_{c 1}(s)=b_{c 1,5} \cdot s^{5}+b_{c 1,4} \cdot s^{4}+b_{c 1,3} \cdot s^{3}+b_{c 1,2} \cdot s^{2}+b_{c 1,1} \cdot s+b_{c 1,0} \\
& b_{c 2}(s)=b_{c 2,4} \cdot s^{4}+b_{c 2,3} \cdot s^{3}+b_{c 2,2} \cdot s^{2}+b_{c 2,1} \cdot s+b_{c 2,0} \\
& b_{p 1}(s)=b_{p 1,5} \cdot s^{5}+b_{p 1,4} \cdot s^{4}+b_{p 1,3} \cdot s^{3}+b_{p 1,2} \cdot s^{2}+b_{p 1,1} \cdot s+b_{p 1,0} \\
& b_{p 2}(s)=b_{p 2,4} \cdot s^{4}+b_{p 2,3} \cdot s^{3}+b_{p 2,2} \cdot s^{2}+b_{p 2,1} \cdot s+b_{p 2,0} \\
& a(s)=a_{6} \cdot s^{6}+a_{5} \cdot s^{5}+a_{4} \cdot s^{4}+a_{3} \cdot s^{3}+a_{2} \cdot s^{2}+a_{1} \cdot s+a_{0}
\end{aligned}
$$

The bloc diagram of the BDFM is illustrated by Figure 2.

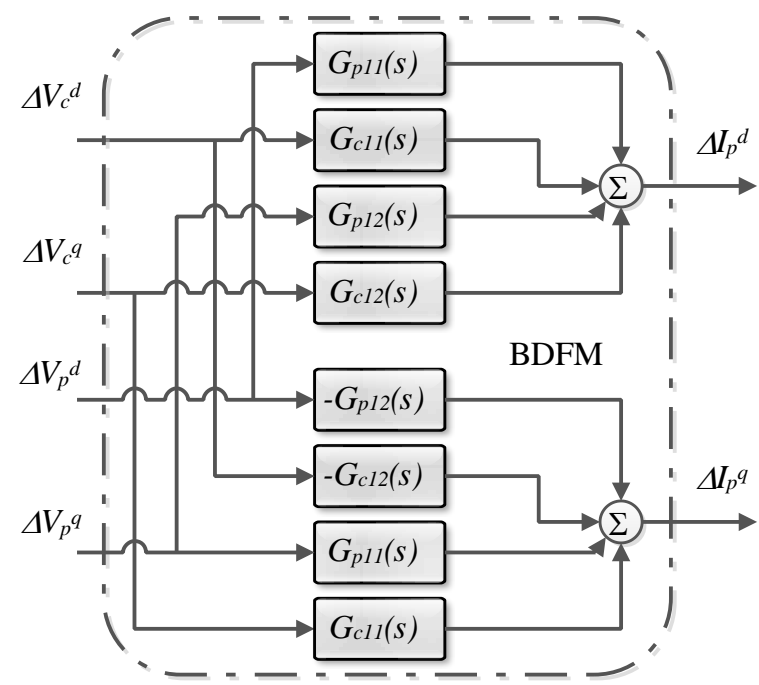

Figure 2. BDFM bloc diagram 
The linearized mathematical model of the BDFM in Eqn. (14) defines a multivariable linear structure in the s-domain which allows application of all tools and techniques made available by linear control theory for stability analysis and controller design of the machine.

Under synchronous conditions the two stator windings will co-operate to induce the same frequency and distribution of currents in the rotor cage and, the synchronous operation speed is equal to:

$$
\omega_{\text {sync }}=\left(\omega_{p}+\omega_{c}\right) /\left(P_{p}+P_{c}\right)
$$

Thus, the synchronous angular frequency of currents and voltages in the stator control winding is given by:

$$
\omega_{c}=\left(p_{p}+p_{c}\right) \omega_{r}-\omega_{p}
$$

Note that the BDFM model depends on the variable rotor's angular speed $\omega_{r o}$ on one hand and, on the less electrical parameters of the machine (resistances, self-inductances, coupling inductances) on the other hand.

\section{Stability Analysis of the BDFM}

In the following, the proposed model is used to carry out a stability analysis of a selected benchmark machine [19]. This machine has one pole pair in the power winding, and three pole pairs in the control winding. The electrical parameters of the prototype are given in Table 1 in the appendix. The simulation results are obtained using Matlab.

\subsection{BDFM Stability Analysis with Respect to the Operating Speed Change}

The first step in the analysis process is the determination of the coefficients of the common denominator $a(s)$ of the transfer matrix element. The result of the calculation of the sixth order polynomial $a(s)$ for the selected BDFM in terms of the rotor's mechanical speed $\omega_{r o}$ is given by:

$$
\begin{aligned}
& a(s)=0.0000034 s^{6}+0.0003763 s^{5}+3.3508583 \times 10^{9}-4239.334 \omega_{r o}{ }^{3}+5.3873311 \omega_{r o}{ }^{4} \\
& +s^{4}\left(1.0217239-0.0107027 \omega_{r o}+0.0000579 \omega_{r o}{ }^{2}\right)+s^{3}\left(74.422331-0.7245816 \omega_{r o}+0.0039397 \omega_{r o}{ }^{2}\right) \\
& +s^{2}\left(101606.71-2130.7525 \omega_{r o}+16.89301 \omega_{r o}{ }^{2}-0.0428108 \omega_{r o}{ }^{3}+0.0000545 \omega_{r o}{ }^{4}\right)+1104273.8 \omega_{r o}{ }^{2} \\
& +s\left(3678634.9-71585.907 \omega_{r o}+515.92339 \omega_{r o}{ }^{2}-1.009245 \omega_{r o}{ }^{3}+0.001285 \omega_{r o}{ }^{4}\right)-1.05747 \times 10^{8} \omega_{r o}
\end{aligned}
$$

Given that some coefficients are functions of the operating velocity $\omega_{r o}$, the positions in the complex domain of the roots of $a(s)$ evolve accordingly and, define six different poles. The Figure 3 shows the evolution of the real part of the conjugate-complex-pairs poles for a velocity varying from zero up to $1500 \mathrm{rpm}$ (1500 rpm represents the double of the synchronous speed $\left.\omega_{\text {sync }}\right)$, and Figure 4 shows the evolution of the imaginary part of the poles for a velocity varying from zero up to $1500 \mathrm{rpm}$.

In fact, for all possible values of rotor's angular velocity, the real part of the poles is always negative, which indicates stable open loop BDFM regardless of the rotor's operating velocity $\omega_{r o}$. Additionally, variations in the imaginary part indicate that the open loop time response of the machine varies with the value of the mechanical velocity. 


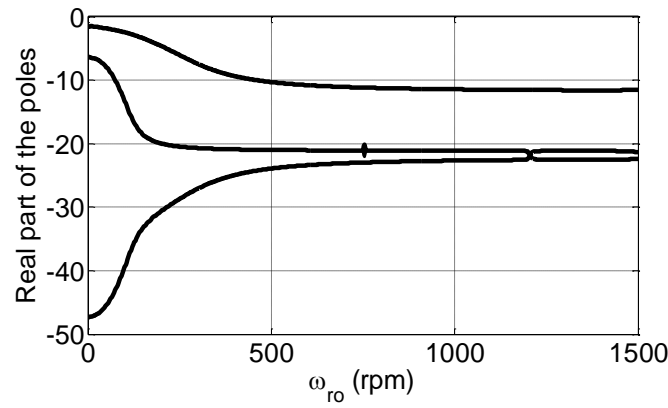

Figure 3. Real part of the poles in function of the operating velocity

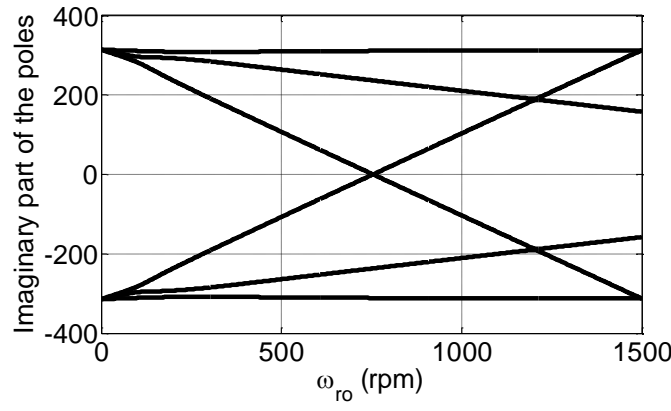

Figure 4. Imaginary part of the poles in function of the operating velocity

\subsection{BDFM Stability Analysis with Respect to Electric Parameters Changes}

Further simulations have been conducted to study the impact of electric parameters changes on the machine stability. Particular interest has been given on the effect of variations in rotor's resistance $R_{r}$ and self-inductance $L_{r}$, as these parameters can undergo significant variations with rotor's temperature increase during machine operation [21-22]. The variation of a parameter $x$ can be expressed as:

$$
x=x_{o} \pm \Delta x
$$

The relative uncertainty in percent has been used rather than the absolute one:

$$
\Delta x(\%)=\left(\frac{x}{x_{o}}-1\right) 100 \%
$$

With the same method, the variation of the eigenvalues can be mapped with respect to any parameter desired. Figures 5 and 6 mapped the real part of the BDFM poles in function of variations in $R_{r}$ and $L_{r}$ respectively when the BDFM turn at rated speed. Only $\pm 50 \%$ of variation in parameters is taken into account. As can be seen, the stability of the BDFM is not altered by any variations in $R_{r}$. However, if the stability is maintained for an increase of up to $50 \%$ in $L_{r}$, the machine becomes open loop unstable for a decrease beyond $16 \%$ in the rotor self-inductance value.

Figures 5 and 6 can be unify into one figure, the Figure 7, which represents the area of stability of the BDFM with respect to variations in both $R_{r}$ and $L_{r}$. The plus mark indicates that the corresponding pair $\left(R_{r}, L_{r}\right)$ has at least one pole has a positive real part, i.e. the BDFM is open loop unstable. While the point mark indicates that all poles of the BDFM for the corresponding pair $\left(R_{r}, L_{r}\right)$ have a negative real part, i.e. the BDFM is open loop stable.

The Figure 7 shows that the rotor resistance variations don't affect the stability of the BDFM. But variations in the rotor self-inductance can destabilize the BDFM. In order to make sure the BDFM stable, variations in $L_{r}$ should not be under $(-16 \%)$ of its nominal value. However, in fault conditions (rotor bars broken) the rotor electric parameters will decrease seriously, so the risk of being unstable will rise dramatically.

Figures 8 and 9 represent the area of stability for variations in resistance and selfinductance of the stator power winding and stator control winding respectively when the rotor turns at rated speed. 

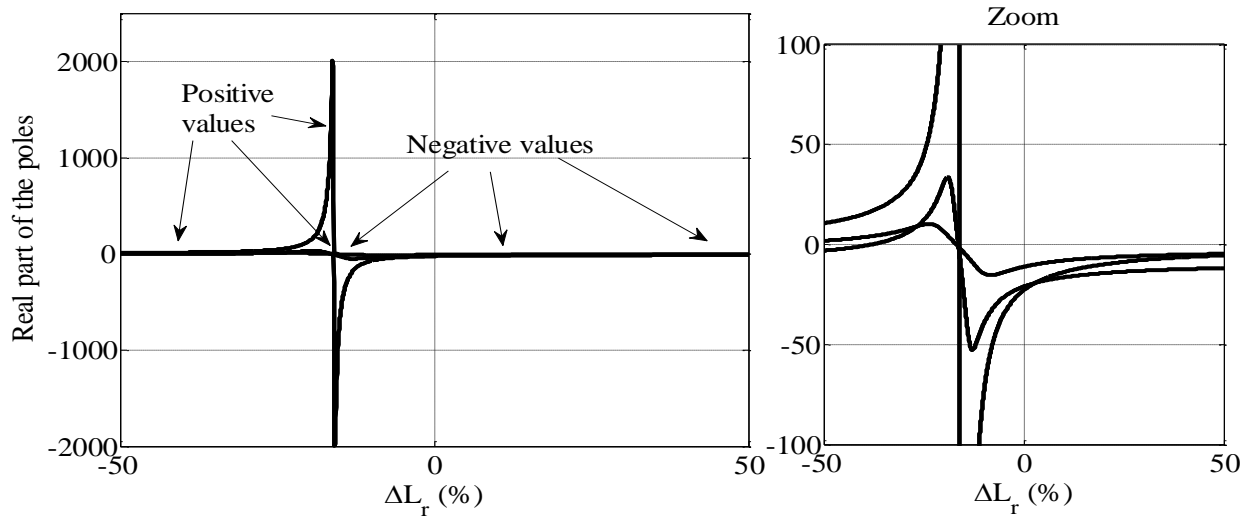

Figure 6. Real part of the poles in function of rotor self-inductance variations

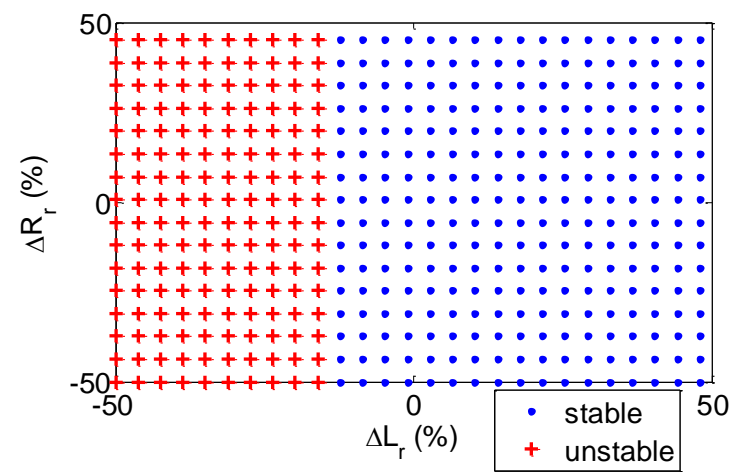

Figure 7. Stability regions with respect to variations in the rotor self-inductance and resistance

As can be seen, variations in $R_{p}$ don't affect the stability of the BDFM, but a decrease in $L_{p}$ by $-20 \%, L_{c}$ by $-30 \%$ or $R_{c}$ by $-40 \%$ from their nominal value can destabilize the BDFM. The decrease in stator electric parameters can be arrived not only due to temperature variation, but also due to fault conditions (short-circuit in electrical winding).

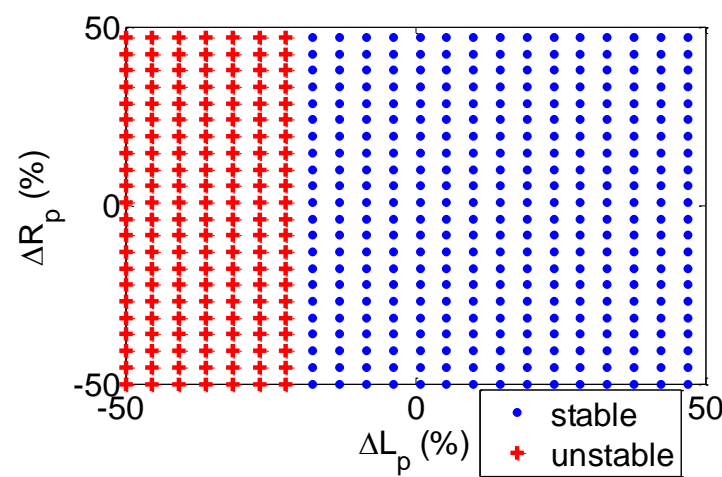

Figure 8. Stability regions with respect to variations in the stator power winding selfinductance and resistance

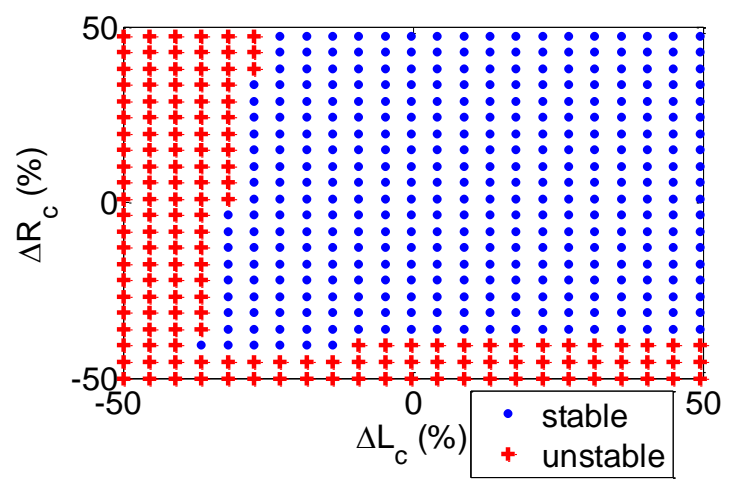

Figure 9. Stability regions with respect to variations in the stator control winding selfinductance and resistance 
By knowing the position of the poles, the behaviour of any BDFM can be predicted on one hand. On the other hand, this approach compared to other studies, give the opportunity to the optimization theory to take place, and contribute before the construction phase to get an optimal BDFM.

\section{Conclusion}

In this paper, a new mathematical model of the brushless doubly fed machine is derived, and a stability analysis is achieved in open loop operation. This study is done for wide operating rotor speed, and for stators and rotor parameters variation. The stability investigation of a selected benchmark BDFM is based on the calculation of the eigenvalues of the open-loop BDFM system. The obtained results indicate that the BDFM is stable over all speed range and, small variations in the electrical parameters don't affect its stability. However, it has been also shown that the BDFM can be unstable especially when one of the self-inductances decreases seriously. A serious diminution in electrical parameters can only happen in the case of shortcircuit in the stator windings or, a break of some rotor bars.

\section{References}

[1] Zhang Z, Meng K, Zhang L. Flicker Measurement and Grey Disaster Prediction of Grid-connected Wind Turbines. TELKOMNIKA (Telecommunication Computing Electronics and Control). 2015; 13(2): 391-400.

[2] Sun P, An B, Long K. Bolt Fatigue Strength for the Tower of Large-scale Horizontal Axis Wind Turbines. TELKOMNIKA (Telecommunication Computing Electronics and Control). 2016; 14(3A): 178-186.

[3] Lamnadi M, Trihi M, Bossoufi B, Boulezhar A. Modeling and control of a doubly-fed induction generator for wind turbine-generator systems. International Journal of Power Electronics and Drive Systems. 2016; 7(3): 982-995.

[4] Elfaki O, Zezhong W, Qihui L. Behavior of DFIG wind turbine during unbalanced grid voltage. Indonesian Journal of Electrical Engineering and Computer Science. 2014; 12(7): 4934-4943.

[5] Kaloi GS, Wang J, Baloch MH. Study of stabilty analysis of a grid connected doubly fed induction generator based on wind energy Application. Indonesian Journal of Electrical Engineering and Computer Science. 2016; 3(2): 305-313.

[6] Zhang $\mathrm{Y}$, Liu H, Zhang $\mathrm{H}$, Zhao X. Performance analysis of doubly excited brushless generator with outer rotor for wind power application. TELKOMNIKA (Telecommunication Computing Electronics and Control). 2012; 10(3): 471-476.

[7] Roberts PC, Long T, McMahon RA, Shao S, Abdi E, Maciejowski JM. Dynamic modelling of the brushless doubly fed machine. IET Electric Power Applications. 2013; 7(7): 544-556.

[8] Hunt LJ. A new type of induction motor. Journal of the Institution of Electrical Engineers. 1907; 39(186): 648-667.

[9] Blazquez F, Veganzones C, Ramirez D, Platero C. Characterization of the rotor magnetic field in a brushless doubly-fed induction machine. IEEE Transactions on Energy Conversion. 2009; 24(3): 599607.

[10] Bouzekri H, Ganouche A, Ahmida Z. Investigation into control performance of brushless doubly fed asynchronous machines in wind energy conversion systems. In Environment and Electrical Engineering (EEEIC), 2015 IEEE 15th International Conference on. Rome. 2015; 1099-1103.

[11] Williamson S, Ferreira AC, Wallace AK. Generalised theory of the brushless doubly-fed machine. I. Analysis. IEE Proceedings-Electric Power Applications. 1997; 144(2): 111-122.

[12] Poza J, Oyarbide E, Roye D, Rodriguez M. Unified reference frame dq model of the brushless doubly fed machine. IEE Proceedings-Electric Power Applications. 2006; 153(5): 726-734.

[13] Cook CD, Smith BH. Stability and stabilisation of doubly-fed single-frame cascade induction machines. In Proceedings of the Institution of Electrical Engineers. 1979; 126(11): 1168-1174.

[14] Cook CD, Smith BH. Effects of machine parameter values on dynamic response and stability regions of doubly-fed cascade induction machines. In IEE Proceedings B-Electric Power Applications. 1983; 130(2): 137-142.

[15] Li R, Wallace A, Spéé R. Determination of converter control algorithms for brushless doubly-fed induction motor drives using Floquet and Lyapunov techniques. IEEE transactions on power electronics. 1995; 10(1): 78-85.

[16] Poza J, Oyarbide E, Roye D, Sarasola I. Stability analysis of a BDFM under open-loop voltage control. In Power Electronics and Applications, 2005 European Conference on. Toulouse. 2005: 10pp. 
[17] Sarasola I, Poza J, Oyarbide E, Rodríguez MÁ. Stability analysis of a brushless doubly-fed machine under closed loop scalar current control. In IEEE Industrial Electronics, IECON 2006-32nd Annual Conference on. Paris. 2006: 1527-1532.

[18] Cárdenas R, Peña R, Wheeler P, Clare J, Munoz A, Sureda A. Control of a wind generation system based on a Brushless Doubly-Fed Induction Generator fed by a matrix converter. Electric Power Systems Research. 2013; 103: 49-60.

[19] Poza J, Oyarbide E, Sarasola I, Rodriguez M. Vector control design and experimental evaluation for the brushless doubly fed machine. IET Electric Power Applications. 2009; 3(4): 247-256.

[20] Rahab A, Senani F, Benalla H. Direct power control of brushless doubly-fed induction generator used in wind energy conversion system. International Journal of Power Electronics and Drive Systems. 2017; 8(1): 417-433.

[21] Agbaje O, Kavanagh DF, Sumisławska M, Howey DA, McCulloch MD, Burnham KJ. Estimation of temperature dependent equivalent circuit parameters for traction-based electric machines. Hybrid and Electric Vehicles Conference 2013. Stevenage. 2013; 1-6.

[22] Sumislawska M, Gyftakis KN, Kavanagh DF, McCulloch M D, Burnham KJ, Howey DA. The impact of thermal degradation on properties of electrical machine winding insulation material. IEEE Transactions on Industry Applications. 2016; 52(4): 2951-2960.

\section{Appendices}

Table 1. BDFM electrical parameters

\begin{tabular}{cccc}
\hline $\begin{array}{c}\text { Electrical } \\
\text { winding }\end{array}$ & resistance $(\Omega)$ & $\begin{array}{c}\text { self inductance } \\
(\mathrm{H})\end{array}$ & $\begin{array}{c}\text { mutual } \\
\text { inductance }(\mathrm{H})\end{array}$ \\
\hline power winding & 1.732 & 0.7184 & 0.2421 \\
control winding & 1.079 & 0.1217 & 0.0598 \\
rotor & 0.473 & 0.1326 & \\
\hline
\end{tabular}

